\title{
A Novel Machine Selection Method Combining Group Eigenvalue Method with TOPSIS Method
}

\author{
Tonghua Yang ${ }^{1,2}$, Shenghua $\mathrm{Xu}^{1}$ and Neal N. Xiong ${ }^{1 *}$ \\ ${ }^{1}$ School of Information Technology, Jiangxi University of Finance and Economics, \\ Nanchang, 330032, China \\ ${ }^{2}$ School of Vocation Teachers, Jiangxi Agricultural University, Nanchang, 330045, \\ China \\ E-mails:Yangth883@163.com,jxcdxsh@foxmail.com,xiongnaixue@gmail.com
}

\begin{abstract}
Machine selection is an important step in the process of manufacturing. The selection process needs to consider some selection attributes simultaneously from a set of candidate machines. The attribute weights are important for the result of machine selection problem, but the most used AHP method has the shortcoming. Thus this paper will develop a new weighting method based on the concept of group eigenvalue method. Then the new machine selection method is proposed by combining group eigenvalue method with TOPSIS method. Two practical examples demonstrate that the proposed method has more effectiveness and feasibility.
\end{abstract}

Keywords: machine selection, group eigenvalue method, multi-attribute decision making, TOPSIS

\section{Introduction}

Fierce economic competition has spurred the manufacturing firms to improve and invest in modern equipment to satisfy the needs of the market [1]. Machine tool selection plays a primary role in the improvement of productivity and flexibility in the manufacturing environment. Manufacturing firms worldwide are forced to undergo transformation processes in order to improve their ability to succeed with their products on extremely competitive international markets [2]. The selection of most desirable machine is to select a best machine from a set of candidate machines according to several given evaluation attributes. The machine selection problem is actually a multi-attribute decision making problem, and it has received great attention by many authors. There are many selection methods are developed for machine selection problem. Nguyen et al. [1] developed the hybrid approach of the fuzzy ANP (Analytic Network Process) and COPRAS-G (Complex Proportional Assessment of alternatives with Grey relations) for machine selection problem with the consideration of the interactions of the attributes. Aloini et al. [2] developed the TOPSIS method for solving packaging machine selection problem, in which the selection attribute are expressed with intuitionistic fuzzy (IF) numbers. Jahromi et al. [3] proposed a novel 0-1 integer programming model for solving a problem of dynamic machine-tool selection and operation allocation with part and tool movement policies under a flexible manufacturing system environment. Moon et al. [4] proposed a $0^{-} 1$ integer programming combining with genetic algorithm for solving the machine tool selection problem. Flexible manufacturing cells (FMCs) have received great attention in today's dynamic manufacturing environment [5]. Under flexible manufacturing system environment, Chtourou et al. [6] developed an expert system for manufacturing systems machine selection; Chan et al. [7-8] put forward a fuzzy goal- 
programming approach to solve the machine tool selection problem. Rao [9] developed the digraph and matrix methods for the machine group selection in a FMC.

This paper will develop a new evaluation method to solve the problem of machine selection in a flexible manufacturing cell. The remains of this paper are organized as follows. In Section 2, this paper is given the introduction of group eigenvalue method. In Section 3, this paper is constructed a MADM model for machine selection problem, and put forward the new evaluation method. In Section 4, two examples of machine selection in flexible manufacturing cell are given to demonstrate the feasibility and effectiveness of the new evaluation method. Finally, Section 5 is given the conclusion and future extend work of this paper.

\section{Group Eigenvalue Method}

Group eigenvalue method, firstly proposed by Qiu in 1997, is a good group decision method [10]. This method fixes the attribute weights by constituting experts' judgment matrix, and this method does not need to test the consistency of judgment matrix. In this point, it is an advantage over AHP method, and thus also leads the group eigenvalue method more simple and convenient [11-16].The detailed conception and steps of group eigenvalue method are given as follows [10]:

It is usually impractical to request perfect evaluation from one expert because one person's knowledge and experience cannot be all-inclusive [17-18]. To integrate experts' evaluations, suppose there is an idealized expert, whose has the highest decision reliability level, and assume the evaluation result of this expert is consistent with those of other experts. The ideal evaluation vector of the idealized expert can be expressed with vector $X^{*}=\left(x_{1}^{*}, x_{2}^{*}, \ldots, x_{n}^{*}\right)^{T}$. The summation of angle values between the idealized expert's evaluation vectors with every other expert's evaluation vector should be the minimum. Thus, $X^{*}$ can be solved out from the following equation:

$$
\max _{\|b\|=1} \sum_{i=1}^{m}\left(b^{T} X_{i}\right)^{2}=\sum_{i=1}^{m}\left(X^{* T} X\right)^{2}=\rho_{\max }
$$

Here $\rho_{\max }$ is the maximum single eigenvalue of matrix $X^{T} X . X^{*}$ is the positive eigenvector corresponding to $\rho_{\max }$ and $\left\|X^{*}\right\|=1$. The parameter $b$ is the weight vector, which satisfies $\forall b=\left(b_{1}, b_{2}, \ldots, b_{n}\right)^{T} \in E^{n}$ and $\|b\|=1$, with $\mathrm{E}$ denoting the Euclid vector space. Each expert's standardized weight vector can be obtained after the eigenvector is normalized corresponding to the maximum eigenvalue.

To obtained attribute weights, the following introduction will give the detail calculation approach:

(i) Calculate the matrix $F=X^{T} X$;

(ii) Then use the Matlab software to obtain the largest eigenvalue $\rho_{\max }$ of matrix F, and then the corresponding eigenvector with respect to $\rho_{\max }$ is $X^{*}=\left(X_{1}^{*}, X_{2}^{*}, \ldots, X_{n}^{*}\right)$.

At last, normalize the eigenvector to form the indicators' weights vector which is also called "the ideal expert's scoring vector".

(iii) Thus the ideal expert's scoring vector, which in this paper is the attribute weight vector with the following form:

$$
W=\left(w_{1}, w_{2}, \ldots, w_{n}\right),
$$

where

$$
w_{j}=X_{j}^{*} / \sum_{k=1}^{m} X_{k}, j=1,2, \ldots, n
$$




\section{New Machine Selection Method}

In this section, we will develop a new machine selection method, the steps of the new method is given as follows:

Step 1. Find out all possible the candidate machines (alternatives), selection attributes and its measures for the given application.

Step 2. Establish the MADM decision matrix.

The solving each MADM problem begins with constructing decision matrix. Let $X=\left\{x_{1}, x_{2}, \cdots, x_{m}\right\}$ be a set of alternative, $O=\left\{o_{1}, o_{2}, \cdots, o_{n}\right\}$ be a set of decision attributes or criteria, $a_{i j}$ is the performance of alternative $x_{i}(i=1,2, \cdots, m)$ on the attribute $o_{j}(j=1,2, \cdots, n)$. Then the machine selection problem can be expressed with the following decision matrix form:

$$
\left.A=\left(a_{i j}\right)_{m \times n}=x_{2} \quad \begin{array}{cccc}
o_{1} & o_{2} & \cdots & o_{n} \\
\vdots \\
x_{11} & a_{12} & \cdots & a_{1 n} \\
a_{21} & a_{22} & \cdots & a_{2 n} \\
\vdots & \vdots & \ddots & \vdots \\
a_{m 1} & a_{m 2} & \cdots & a_{m n}
\end{array}\right)
$$

Step 3. Normalize the decision matrix $A$ into normalization decision matrix $R=\left(r_{i j}\right)_{m \times n}$.

The process of transforming attributes value into a range of $[0,1]$ is called normalization and it is required in MADM methods to transform performance rating with different data measurement unit in a decision matrix into a compatible unit [19-21]. The normalization method adopted from the paper [22], and the formulas are given as follows:

$$
r_{i j}=x_{i j} / \sqrt{\sum_{i=1}^{m} x_{i j}^{2}}
$$

Step 4. Define the positive ideal solution (PIS) and the negative ideal solution (NIS).

The PIS is $r^{*}=\left(r_{1}^{*}, r_{2}^{*}, \cdots, r_{n}^{*}\right)$; The NIS is $r^{-}=\left(r_{1}^{-}, r_{2}^{-}, \cdots, r_{n}^{-}\right)$. Here, if the $j$-th attribute is the benefit attribute, which is the larger the better attribute, then $r_{j}^{*}=\max _{1 \leq i \leq m}\left\{a_{i j}\right\}$, $r_{j}^{-}=\min _{1 \leq i \leq m}\left\{a_{i j}\right\}$; If the $\mathrm{j}$-th attribute is the cost attribute, which is the smaller the better attribute, then $r_{j}^{*}=\min _{1 \leq i \leq m}\left\{a_{i j}\right\}, r_{j}^{-}=\max _{1 \leq i \leq m}\left\{a_{i j}\right\}$.

Step 5. Calculate the distance measure for each alternative to PIS and NIS using the following equations:

$$
D_{i}^{*}=\sqrt{\sum_{j=1}^{n} w_{i}^{2}\left(r_{i j}-r_{j}^{*}\right)^{2}}
$$

and

$$
D_{i}^{-}=\sqrt{\sum_{j=1}^{n} w_{i}^{2}\left(r_{i j}-r_{j}^{-}\right)^{2}}
$$

Step 6. Calculate the relative closeness to the ideal solution according to the following equation:

$$
C_{i}=\frac{D_{i}^{-}}{D_{i}^{-}+D_{i}^{*}}, i=1,2, \ldots, m
$$

Step 7. Rank all the alternatives $x_{i}$ in accordance with the values of relative closeness degree $C_{i}(i=1,2 \ldots, m)$. The larger the value of $C_{i}$ the better of alternative $x_{i}$. 


\section{Case Study}

Example 1. This example is taken from the case study conducted by Wang et al. [23]. The factory manager decided to purchase some machine facilities after sufficient discussion and complete evaluation. There are ten candidate machines $x_{1}, \ldots, x_{10}$ are waited to be evaluated according to the following four attributes: Total purchasing cost (dollars) $\left(o_{1}\right)$, Total floor space $(\mathrm{m} 2)\left(o_{2}\right)$, Total machine number $\left(o_{3}\right)$, Productivity $(\mathrm{mm} / \mathrm{min})\left(o_{4}\right)$. Here are the cost attributes, and others are benefit attributes. The original evaluation values are shown in Table 1 [23].

Table 1. Decision Matrix and Normalized Decision Matrix for Machine Group Selection in an FMC

\begin{tabular}{|c|c|c|c|c|c|c|c|c|c|}
\hline \multirow{2}{*}{ No. } & \multicolumn{4}{|c|}{ Evaluation attribute values } & \multirow{2}{*}{ No. } & \multicolumn{4}{|c|}{ Evaluation attribute values } \\
\hline & $o_{1}$ & $o_{2}$ & $o_{3}$ & $o_{4}$ & & $o_{1}$ & $o_{2}$ & $o_{3}$ & $O_{4}$ \\
\hline 1 & 581818 & 54.49 & 3 & 5500 & 1 & 0.1073 & 0.0904 & 0.0857 & 0.0993 \\
\hline 2 & 595454 & 49.73 & 3 & 4500 & 2 & 0.1098 & 0.0825 & 0.0857 & 0.0812 \\
\hline 3 & 586060 & 51.24 & 3 & 5000 & 3 & 0.1081 & 0.0850 & 0.0857 & 0.0903 \\
\hline 4 & 522727 & 45.71 & 3 & 5800 & 4 & 0.0964 & 0.0758 & 0.0857 & 0.1047 \\
\hline 5 & 561818 & 52.66 & 3 & 5200 & 5 & 0.1036 & 0.0873 & 0.0857 & 0.0939 \\
\hline 6 & 543030 & 74.46 & 4 & 5600 & 6 & 0.1001 & 0.1235 & 0.1143 & 0.1011 \\
\hline 7 & 522727 & 75.42 & 4 & 5800 & 7 & 0.0964 & 0.1251 & 0.1143 & 0.1047 \\
\hline 8 & 486970 & 62.62 & 4 & 5600 & 8 & 0.0898 & 0.1039 & 0.1143 & 0.1011 \\
\hline 9 & 509394 & 65.87 & 4 & 6400 & 9 & 0.0939 & 0.1093 & 0.1143 & 0.1155 \\
\hline 10 & 513333 & 70.67 & 4 & 6000 & 10 & 0.0947 & 0.1172 & 0.1143 & 0.1083 \\
\hline
\end{tabular}

The specific calculation steps of the proposed method are given as follows:

Step 1. The normalized attribute values are reported in Table1;

Step 2. In order to determine the relative weight of each criterion affecting the machine selection decision, a pair-wise comparison matrix, as shown in Table 2.

Table 2. Pair-Wise Comparison Matrix

\begin{tabular}{|c|c|c|c|c|}
\hline Criteria & Cost & Total floor space & Total machine number & Productivity \\
\hline Cost & 1 & $1 / 3$ & $1 / 4$ & $1 / 2$ \\
\hline Total floor space & 3 & 1 & $1 / 2$ & 2 \\
\hline Total machine number & 4 & 2 & 1 & 3 \\
\hline Productivity & 2 & $1 / 2$ & $1 / 3$ & 1 \\
\hline
\end{tabular}

Using the group eigenvalue method, the attribute weights are obtained as follows: $\mathrm{W}=(0.4306,0.1797,0.0930,0.2967)$

Step 3. The positive ideal solution (PIS) and the negative ideal solution (NIS) are: $\mathrm{PIS}=(0.1098,0.1251,0.1143,0.0812)$ and NIS $=(0.0898,0.0758,0.0857,0.1155)$.

Step 4. The distance measures for each alternative to PIS (NIS) and the relative closeness are reported in Table 3.

Table 3. Distance Measures, the Relative Closeness and Ranking Result

\begin{tabular}{cccrrrrrrrr}
\hline & $x_{1}$ & $x_{2}$ & $x_{3}$ & $x_{4}$ & $x_{5}$ & $x_{6}$ & $x_{7}$ & $x_{8}$ & $x_{9}$ & $x_{10}$ \\
\hline$D_{i}^{*}$ & 0.0294 & 0.0422 & 0.0346 & 0.0135 & 0.0283 & 0.0341 & 0.0318 & 0.0223 & 0.0212 & 0.0264 \\
$D_{i}^{-}$ & 0.0273 & 0.0253 & 0.0255 & 0.0405 & 0.0270 & 0.0227 & 0.0285 & 0.0350 & 0.0396 & 0.0329 \\
$C_{i}$ & 0.4815 & 0.3746 & 0.4240 & 0.7500 & 0.4875 & 0.4003 & 0.4724 & 0.6106 & 0.6510 & 0.5550 \\
$\begin{array}{c}\text { Ranking } \\
\text { result }\end{array}$ & 6 & 10 & 8 & 1 & 5 & 9 & 7 & 3 & 2 & 4 \\
\hline
\end{tabular}


Then the ranking order is $4-9-8-10-5-1-7-3-6-2$, which is the same as the one obtained in paper [19] using AHP method, and almost the same as the result using TOPSIS method as : $4-9-8-10-7-5-1-6-3-2$. The desirable machine is the machine No. 4.

\section{Example 2.}

This example is taken from the case study conducted by Sun [24], which applied data envelopment analysis (DEA) to evaluate $21 \mathrm{CNC}$ machines (lathes) in terms of system specifications and cost at the operational level. It aims at identifying a homogenous set of good systems, by measuring, for each machine, according to some attributes: the capital cost of a CNC machine, quoted in New Taiwanese Dollar (NT\$), work capacity, machine body, spindle and tool turret. Work capacity is measured by the maximum machining diameter $(\mathrm{mm})$ and machining length $(\mathrm{mm})$. The machine body is measured by rapid traverse rates $(\mathrm{m} / \mathrm{min})$ of the $\mathrm{X}$-axis and Z-axis. Rapid traverse rates of the $\mathrm{X}$ and $\mathrm{Z}$-axes reflect the positioning capability of a turning center. The spindle is measured by spindle speed range (rpm). Spindle speed is the number of revolutions that a spindle can make in one minute and it allows a machine to maintain a constant cutting speed regardless of the part diameter. The tool turret is measured by the tool capacity. The fewer is the number of tools in the turret, the more is the time required to change the tools as selected for use in a particular program. Thus, seven criteria, i.e. capital cost (CC) spindle speed range (SS), tool capacity (TC), rapid traverse rate of X-axis (TX), rapid traverse rate of Z-axis (TZ), maximum machining diameter (MD) and maximum machining length (ML) are considered that affect the ability of a CNC machine to perform various manufacturing operations. In this example, the most suitable CNC machine is selected for small-size shell production from the available alternatives using TOPSIS method.

Table 4. Quantitative Information for 21 CNC Lathes [24]

\begin{tabular}{|c|c|c|c|c|c|c|c|c|}
\hline \multirow[b]{2}{*}{ No. } & \multirow[b]{2}{*}{ CNC Lathe } & \multicolumn{6}{|c|}{ Evaluation attribute values } & \multirow[b]{2}{*}{$\operatorname{ML}\left(o_{7}\right)$} \\
\hline & & $\mathrm{CC}\left(o_{1}\right)$ & $\mathrm{SS}\left(o_{2}\right.$ & $\mathrm{TC}\left(o_{3}\right)$ & $\operatorname{TX}\left(o_{4}\right)$ & $\mathrm{TZ}\left(o_{5}\right)$ & $\operatorname{MD}\left(o_{6}\right)$ & \\
\hline 1 & YANG ML-5A & 1200000 & 5590 & 8 & 24 & 24 & 205 & 350 \\
\hline 2 & YANG ML-25A & 1550000 & 3465 & 8 & 20 & 20 & 280 & 520 \\
\hline 3 & YCM TC-15 & 1400000 & 5950 & 12 & 15 & 20 & 250 & 469 \\
\hline 4 & VTURN16 & 1100000 & 5940 & 12 & 12 & 15 & 230 & 600 \\
\hline 5 & FEMCO HL-15 & 1200000 & 5940 & 12 & 12 & 16 & 150 & 330 \\
\hline 6 & FEMCO WNCL-20 & 1500000 & 3465 & 12 & 6 & 12 & 260 & 420 \\
\hline 7 & FEMCO WNCL-30 & 2600000 & 3960 & 12 & 12 & 16 & 300 & 625 \\
\hline 8 & EX-106 & 1320000 & 4950 & 12 & 24 & 30 & 240 & 340 \\
\hline 9 & ECOCA SJ20 & 1180000 & 4480 & 8 & 24 & 24 & 250 & 330 \\
\hline 10 & ECOCA SJ25 & 1550000 & 3950 & 12 & 15 & 20 & 280 & 460 \\
\hline 11 & ECCOA SJ30 & 1600000 & 3450 & 12 & 15 & 20 & 280 & 460 \\
\hline 12 & TOPPER TNL-85A & 1200000 & 3465 & 8 & 20 & 24 & 264 & 400 \\
\hline 13 & TOPPER TNL-100A & 1350000 & 2970 & 8 & 20 & 24 & 264 & 400 \\
\hline 14 & $\begin{array}{c}\text { TOPPER TNL- } \\
\text { 100AL }\end{array}$ & 1400000 & 2970 & 12 & 24 & 30 & 300 & 600 \\
\hline 15 & TOPPER TNL-85T & 1350000 & 3465 & 12 & 30 & 30 & 264 & 350 \\
\hline 16 & TOPPER TNL-100T & 1450000 & 2970 & 12 & 20 & 24 & 300 & 400 \\
\hline 17 & TOPPERTNL-120T & 1520000 & 2475 & 12 & 20 & 24 & 300 & 400 \\
\hline
\end{tabular}




\begin{tabular}{ccccccccc}
\hline 18 & ATECH MT-52S & 1376000 & 4752 & 12 & 20 & 24 & 235 & 350 \\
19 & ATECH MT-52L & 1440000 & 4752 & 12 & 20 & 24 & 235 & 600 \\
20 & ATECH MT-75S & 1824000 & 3790 & 10 & 12 & 20 & 300 & 530 \\
21 & ATECH MT-75L & 1920000 & 3790 & 10 & 12 & 20 & 300 & 1030 \\
\hline
\end{tabular}

The specific calculation steps of the proposed method are given as follows:

Step 1. As all these criteria considered for selecting the proper CNC machine having different units and dimensions, their values are first normalized using Eq. (1). The normalized attribute values are reported in Table 5.

Table 5. Normalized Decision Matrix of Quantitative Information for 21 CNC Lathes [24]

\begin{tabular}{|c|c|c|c|c|c|c|c|c|}
\hline \multirow[b]{2}{*}{ No. } & \multirow[b]{2}{*}{ CNC Lathe } & \multicolumn{6}{|c|}{ Evaluation attribute values } & \multirow[b]{2}{*}{$\mathrm{ML}\left(o_{7}\right)$} \\
\hline & & $\mathrm{CC}\left(o_{1}\right)$ & $\operatorname{SS}\left(o_{2}\right)$ & $\begin{array}{c}\mathrm{TC}\left(o_{3}\right. \\
) \\
\end{array}$ & $\operatorname{TX}\left(o_{4}\right)$ & $\begin{array}{c}\mathrm{TZ} \\
\left(o_{5}\right) \\
\end{array}$ & $\operatorname{MD}\left(o_{6}\right)$ & \\
\hline 1 & YANG ML-5A & 0.1732 & 0.2870 & 0.1589 & 0.2783 & 0.2332 & 0.1695 & 0.1529 \\
\hline 2 & YANG ML-25A & 0.2237 & 0.1779 & 0.1589 & 0.2319 & 0.1944 & 0.2315 & 0.2271 \\
\hline 3 & YCM TC-15 & 0.2021 & 0.3054 & 0.2383 & 0.1740 & 0.1944 & 0.2067 & 0.2048 \\
\hline 4 & VTURN16 & 0.1588 & 0.3049 & 0.2383 & 0.1392 & 0.1458 & 0.1902 & 0.2620 \\
\hline 5 & FEMCO HL-15 & 0.1732 & 0.3049 & 0.2383 & 0.1392 & 0.1555 & 0.1240 & 0.1441 \\
\hline 6 & FEMCO WNCL-20 & 0.2165 & 0.1779 & 0.2383 & 0.0696 & 0.1166 & 0.2150 & 0.1834 \\
\hline 7 & FEMCO WNCL-30 & 0.3753 & 0.2033 & 0.2383 & 0.1392 & 0.1555 & 0.2481 & 0.2729 \\
\hline 8 & EX-106 & 0.1905 & 0.2541 & 0.2383 & 0.2783 & 0.2915 & 0.1985 & 0.1485 \\
\hline 9 & ECOCA SJ20 & 0.1703 & 0.2300 & 0.1589 & 0.2783 & 0.2332 & 0.2067 & 0.1441 \\
\hline 10 & ECOCA SJ25 & 0.2237 & 0.2028 & 0.2383 & 0.1740 & 0.1944 & 0.2315 & 0.2009 \\
\hline 11 & ECCOA SJ30 & 0.2309 & 0.1771 & 0.2383 & 0.1740 & 0.1944 & 0.2315 & 0.2009 \\
\hline 12 & TOPPER TNL-85A & 0.1732 & 0.1779 & 0.1589 & 0.2319 & 0.2332 & 0.2183 & 0.1747 \\
\hline 13 & TOPPER TNL-100A & 0.1949 & 0.1525 & 0.1589 & 0.2319 & 0.2332 & 0.2183 & 0.1747 \\
\hline 14 & $\begin{array}{c}\text { TOPPER TNL- } \\
\text { 100AL }\end{array}$ & 0.2021 & 0.1525 & 0.2383 & 0.2783 & 0.2915 & 0.2481 & 0.2620 \\
\hline 15 & TOPPER TNL-85T & 0.1949 & 0.1779 & 0.2383 & 0.3479 & 0.2915 & 0.2183 & 0.1529 \\
\hline 16 & TOPPER TNL-100T & 0.2093 & 0.1525 & 0.2383 & 0.2319 & 0.2332 & 0.2481 & 0.1747 \\
\hline 17 & TOPPERTNL-120T & 0.2194 & 0.1271 & 0.2383 & 0.2319 & 0.2332 & 0.2481 & 0.1747 \\
\hline 18 & ATECH MT-52S & 0.1986 & 0.2439 & 0.2383 & 0.2319 & 0.2332 & 0.1943 & 0.1529 \\
\hline 19 & ATECH MT-52L & 0.2079 & 0.2439 & 0.2383 & 0.2319 & 0.2332 & 0.1943 & 0.2620 \\
\hline 20 & ATECH MT-75S & 0.2633 & 0.1946 & 0.1986 & 0.1392 & 0.1944 & 0.2481 & 0.2315 \\
\hline 21 & ATECH MT-75L & 0.2771 & 0.1946 & 0.1986 & 0.1392 & 0.1944 & 0.2481 & 0.4498 \\
\hline
\end{tabular}

Step 2. In order to determine the relative normalized weight of each criterion affecting the $\mathrm{CNC}$ machine selection decision, a pair-wise comparison matrix, as shown in Table 6. 
Table 6. Pair-Wise Comparison Matrix

\begin{tabular}{|c|c|c|c|c|c|c|c|}
\hline $\begin{array}{c}\text { Criteri } \\
\mathrm{a}\end{array}$ & $\mathrm{CC}$ & $\mathrm{SS}$ & $\mathrm{TC}$ & $\mathrm{TX}$ & $\mathrm{TZ}$ & $\mathrm{MD}$ & $\mathrm{ML}$ \\
\hline $\mathrm{CC}$ & 1 & 1 & 1 & $1 / 2$ & 1 & $1 / 2$ & 1 \\
\hline $\mathrm{SS}$ & 1 & 1 & 1 & 1 & 1 & 3 & 2 \\
\hline $\mathrm{TC}$ & 1 & 1 & 1 & 1 & 2 & 2 & 2 \\
\hline $\mathrm{TX}$ & 2 & 1 & 1 & 1 & $1 / 2$ & $1 / 3$ & 1 \\
\hline $\mathrm{TZ}$ & 1 & 1 & $1 / 2$ & 2 & 1 & $1 / 2$ & $1 / 2$ \\
\hline $\mathrm{MD}$ & 2 & $1 / 3$ & $1 / 2$ & 3 & 2 & 1 & 1 \\
\hline $\mathrm{ML}$ & 1 & $1 / 2$ & $1 / 2$ & 1 & 2 & 1 & 1 \\
\hline
\end{tabular}

Using the group eigenvalue method, the attribute weights are obtained as follows: $\mathrm{W}=(0.0999,0.1764,0.1777,0.1152,0.1158,0.1863,0.1287)$

Among the seven criteria, CC, TX and TZ is the non-beneficial attribute as their lower values are desirable; on the other hand, SS, TC, MD and ML is the beneficial attribute because their higher values are always preferable. Table 1 shows the criteria values for 21 alternative $\mathrm{CNC}$ machines (lathes).

Step 3. The positive ideal solution (PIS) and the negative ideal solution (NIS) are :

PIS $=(0.1588,0.3054,0.1589,0.3479,0.1166,0.2481,0.4498)$

and

$\mathrm{NIS}=(0.3753,0.1271,0.2383,0.0696,0.2915,0.1240,0.1441)$.

Step 4.The distance measures for each alternative to PIS (NIS) and the relative closeness are reported in Table 7.

Table 7. Distance Measures, the Relative Closeness and Ranking Result

\begin{tabular}{|c|c|c|c|c|}
\hline Alternative & $D_{i}^{*}$ & $D_{i}^{-}$ & $C_{i}$ & Ranking result \\
\hline$x_{1}$ & 0.0440 & 0.0458 & 0.5102 & 3 \\
\hline$x_{2}$ & 0.0405 & 0.0387 & 0.4889 & 6 \\
\hline$x_{3}$ & 0.0419 & 0.0431 & 0.5072 & 5 \\
\hline$x_{4}$ & 0.0386 & 0.0467 & 0.5476 & 2 \\
\hline$x_{5}$ & 0.0537 & 0.0413 & 0.4347 & 13 \\
\hline$x_{6}$ & 0.0546 & 0.0325 & 0.3729 & 21 \\
\hline$x_{7}$ & 0.0459 & 0.0361 & 0.4400 & 12 \\
\hline$x_{8}$ & 0.0485 & 0.0402 & 0.4528 & 9 \\
\hline$x_{9}$ & 0.0451 & 0.0425 & 0.4854 & 7 \\
\hline$x_{10}$ & 0.0457 & 0.0337 & 0.4241 & 16 \\
\hline$x_{11}$ & 0.0478 & 0.0318 & 0.3996 & 19 \\
\hline$x_{12}$ & 0.0464 & 0.0375 & 0.4469 & 11 \\
\hline$x_{13}$ & 0.0489 & 0.0355 & 0.4211 & 17 \\
\hline$x_{14}$ & 0.0448 & 0.0408 & 0.4766 & 8 \\
\hline$x_{15}$ & 0.0512 & 0.0418 & 0.4492 & 10 \\
\hline$x_{16}$ & 0.0507 & 0.0352 & 0.4099 & 18 \\
\hline
\end{tabular}




\begin{tabular}{|l|l|l|l|l|}
\hline$x_{17}$ & 0.0533 & 0.0345 & 0.3926 & 20 \\
\hline$x_{18}$ & 0.0475 & 0.0361 & 0.4320 & 15 \\
\hline$x_{19}$ & 0.0372 & 0.0388 & 0.5100 & 4 \\
\hline$x_{20}$ & 0.0446 & 0.0342 & 0.4337 & 14 \\
\hline$x_{21}$ & 0.0351 & 0.0506 & 0.5905 & 1 \\
\hline
\end{tabular}

Then the ranking order is $21-4-1-19-3-2-9-14-8-15-12-7-5-20-18-$ $10-13-16-11-17-6$, which is almost the same as the one obtained in paper [24-25] using DEA method.

\section{Conclusion}

For the machine selection problem under flexible manufacturing system environment, we propose a new evaluation method. We first establish a MADM model for machine selection problem, and then develop group eigenvalue method to determine the attributes. Group eigenvalue method is an easy weighting method, and has some advantage over AHP method. Then the new machine selection method is proposed combining group eigenvalue method with TOPSIS method. A practical example is used to show the effective and feasible of the proposed method. The new method is easy and can be finished by computer software, such as Excel, matlab, and thus can be a suitable method for manufacturing firms.

For the future, we will extend the proposed for other management decision problems, such as material selection, robot selection, water quality evaluation etc. We will further develop new evaluation method for machine selection problem and extend evaluation methods for fuzzy machine selection problem which the evaluation attributes are expressed by fuzzy numbers, such as interval numbers, triangular fuzzy numbers.

\section{Acknowledgments}

This work is partially supported by National Natural Science Foundation of China (No. 71261009).

\section{References}

[1] H. T. Nguyen, S. Z. M. Dawal, Y. Nukman and H. Aoyama, "A hybrid approach for fuzzy multiattribute decision making in machine tool selection with consideration of the interactions of attributes", Expert Systems with Applications, vol. 41, (2014), pp. 3078-3090.

[2] D. Aloini, R. Dulmin and V. Mininno, "A peer IF-TOPSIS based decision support system for packaging machine selection", Expert Systems with Applications, vol. 41, (2014), pp. 2157-2165.

[3] M. H. M. A. Jahromi and R. T. Moghaddam, "A novel 0-1 linear integer programming model for dynamic machine-tool selection and operation allocation in a flexible manufacturing system", Journal of Manufacturing Systems, vol. 31, (2012), pp. 224-231.

[4] C. Moon, M. Lee, Y. Seo and Y. H. Lee”, Integrated machine tool selection and operation sequencing with capacity and precedence constraints using genetic algorithm", Computers \& Industrial Engineering, vol. 43, (2002), pp. 605-621.

[5] R. V. Rao, "Decision Making in Manufacturing Environment Using Graph Theory and Fuzzy Multiple Attribute Decision Making Methods", Springier-Verlag, London, (2013).

[6] H. Chtourou, W. Masmoudi and A. Maalej, "An expert system for manufacturing systems machine selection”, Expert Syst Appl, vol. 28, (2005), pp. 461-467.

[7] F. T. S. Chan and R. Swarnkar, "Ant colony optimization approach to a fuzzy goal programming model for a machine tool selection and operation allocation problem in an FMS", Robot Computer Integer Manuf, vol. 22, (2006), pp. 353-362.

[8] F. T. S. Chan, R. Swarnakar and M. K. Tiwari, "Fuzzy goal-programming model with an artificial immune system (AIS) approach for a machine tool selection and operation allocation problem in a 
flexible manufacturing system", International Journal of Production Research, vol. 43, (2005), pp. 41474163 .

[9] R. V. Rao, "Machine group selection in a flexible manufacturing cell using digraph and matrix methods", International Journal Ind Syst Eng, vol. 1 (2006), pp .502-518.

[10] W. H, Qiu, "Group eigenvalue method", Applied Mathematics and Mechanics, vol. 18, no. 11, (1997), pp. 1027-1031.

[11] J. J. Luo, J. J. Zheng, L. Sun and S. B. Zhang, "An entropy-based multi-criterion group decision analysis method of selecting the optimum weak-subgrade treatment", Journal of Chongqing University: English Edition, vol. 7, no. 3, (2008), pp. 191-197.

[12] L. J. Jia and D. C. Fan, "A study of low carbon technology innovation project evaluation", Science \& Technology Progress and Policy, vol. 29, no. 1, (2012), pp. 128-132.

[13] M. A. Ying, "Relative Efficiency evaluation on water resource utilization", Journal of Northeast Agricultural University (English Edition), vol. 18, no. 3, (2011), pp. 60-64.

[14] C. Kahraman, U. Cebeci and Z. Ulukan, "Multi-criteria supplier selection using fuzzy AHP", Logistics Information Management, vol. 16, (2003), pp. 382-394.

[15] M. C. Das, B. Sarkar and S. Ray, "Decision making under conflicting environment: A new MCDM method", International Journal of Applied Decision Sciences, vol. 5, (2012), pp. 142-162.

[16] O. Durán and J. Aguilo, "Computer-aided machine-tool selection based on a fuzzy-AHP approach", Expert Systems with Applications, vol. 34, (2008), pp. 1787-1794.

[17] W. Z. Liu, "Group Eigenvalue Method for Food Supplier Selection Model with Ordinal Interval Preference Information", Advanced Journal of Food Science and Technology. vol. 6, (2014), pp. 711714.

[18] H. Chtourou, W. Masmoudi and A. Maalej, "An expert system for manufacturing systems machine selection", Expert Syst Appl, vol. 28, no. 3, (2005), pp. 461-467.

[19] K. Maniya and M. G. Bhatt, "A selection of material using a novel type decision-making method: Preference selection index method", Materials and Design, vol. 31 (2010), pp. 1785-1789.

[20] R. Rai, S. Kameshwaran and M. K. Tiwari, "Machine tool selection and operation allocation in FMS: Solving a fuzzy goal-programming model using a genetic algorithm", International Journal of Production Research, vol. 40, (2002), pp. 641-665.

[21] A. Sadhu and S. Chakraborty, "Non-traditional machining processes selection using data envelopment analysis", Expert Systems with Applications, vol. 38, (2011), pp. 8770-8781.

[22] R. V. Rao, "Decision Making in Manufacturing Environment Using Graph Theory and Fuzzy Multiple Attribute Decision Making Methods", Springer-Verlag, London, (2007).

[23] T. Y. Wang, C. F. Shaw and Y. L. Chen, "Machine selection in flexible manufacturing cell: a fuzzy multiple attribute decision making approach", International Journal Prod Res, vol. 38, (2000), pp. 20792097.

[24] S. Sun, "Assessing computer numerical control machines using data envelopment analysis", International Journal of Production Research, vol. 40, (2002), pp. 2011-2039.

[25] S. T. Liu, "A fuzzy DEA/AR approach to the selection of flexible manufacturing systems", Computer Ind Eng, vol. 54, no. 1, (2008), pp. 66-76.

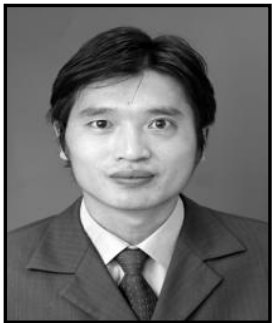

\section{Authors}

Tonghua Yang, he is currently a doctoral student at School of Information Technology, Jiangxi University of Finance and Economics, China. He current major research fields include information management and knowledge management.

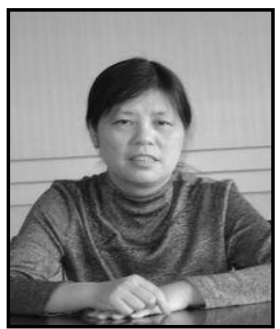

Shenghua $\mathrm{Xu}$, she is a chief professor and doctoral supervisor in management science and engineering at Jiangxi University of Finance and Economics, China. She is also the associate chairman of academic committee in School of Information Technology. She has published about more than 50 research papers (including about 20 SCI/EI-indexed papers) and 2 books. Her current major research fields include information management and knowledge management. 


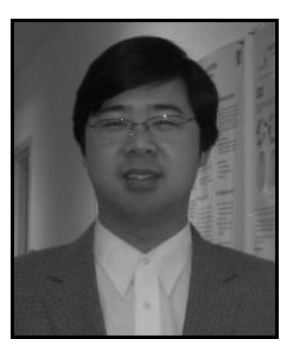

Naixue Xiong, he is current a faculty at Dept. of Business and Computer Science (BCS), Southwestern Oklahoma State University (SWOSU), OK, USA. He received his both $\mathrm{PhD}$ degrees in Wuhan University (about software engineering), and Japan Advanced Institute of Science and Technology (about dependable networks), respectively. Before he attends SWOSU, he worked in Colorado Technical University, Wentworth Technology Institution, and Georgia State University for many years. His research interests include Cloud Computing, Business Networks, Security and Dependability, Parallel and Distributed Computing, and Optimization Theory.

Dr./Prof. Xiong published over 100 international journal papers. He served as an Editor-in-Chief, Associate editor or Editor member for over 10 international journals (including Associate Editor for IEEE Tran. on Systems, Man \& Cybernetics: Systems, Associate Editor for Information Science, Editor-in-Chief for Journal of Internet Technology (JIT), and Editor-in-Chief for Journal of Parallel \& Cloud Computing (PCC)). Dr./Prof. Xiong is the Chair of "Trusted Cloud Computing" Task Force, IEEE Computational Intelligence Society (CIS), http://www.cs.gsu.edu/ cscnxx/index-TF.html, and the Industry System Applications Technical Committee, http://ieeecis.org/technical/isatc/; He is a senior member of IEEE Computer Society. E-mail: xiongnaixue@gmail.com, neal.xiong@ swosu.edu. 